\title{
Northward expansion trends and future potential distribution of a dragonfly Ischnura senegalensis Rambur under climate change using citizen science data in South Korea
}

Sookyung Shin ${ }^{1}$, Kwang Soo Jung ${ }^{2}$, Hong Gu Kang ${ }^{3}$, Ji-Hee Dang ${ }^{1}$, Doohee Kang ${ }^{1}$, Jeong Eun Han ${ }^{1}$ and Jin Han Kim ${ }^{1 *}$

\begin{abstract}
Background: Citizen science is becoming a mainstream approach of baseline data collection to monitor biodiversity and climate change. Dragonflies (Odonata) have been ranked as the highest priority group in biodiversity monitoring for global warming. Ischnura senegalensis Rambur has been designated a biological indicator of climate change and is being monitored by the citizen science project "Korean Biodiversity Observation Network." This study has been performed to understand changes in the distribution range of I. senegalensis in response to climate change using citizen science data in South Korea.

Results: We constructed a dataset of 397 distribution records for I. senegalensis, ranging from 1980 to 2020. The number of records sharply increased over time and space, and in particular, citizen science monitoring data accounted for the greatest proportion (58.7\%) and covered the widest geographical range. This species was only distributed in the southern provinces until 2010 but was recorded in the higher latitudes such as Gangwon-do, Incheon, Seoul, and Gyeonggi-do (max. Paju-si, 37.70 latitude) by 2020. A species distribution model showed that the annual mean temperature (Bio1; 63.2\%) and the maximum temperature of the warmest month (Bio5; 16.7\%) were the most critical factors influencing its distribution. Future climate change scenarios have predicted an increase in suitable habitats for this species.
\end{abstract}

Conclusions: This study is the first to show the northward expansion in the distribution range of I. senegalensis in response to climate warming in South Korea over the past 40 years. In particular, citizen science was crucial in supplying critical baseline data to detect the distribution change toward higher latitudes. Our results provide new insights on the value of citizen science as a tool for detecting the impact of climate change on ecosystems in South Korea.

Keywords: Citizen science, Climate-sensitive biological indicator species, Global warming, Ischnura senegalensis, Korean Biodiversity Observation Network, Northward shifts, Species distribution model

\footnotetext{
* Correspondence: birdkr@korea.kr

'Department of Biological Resources Utilization, National Institute of

Biological Resources, Incheon 22689, Republic of Korea

Full list of author information is available at the end of the article
}

(c) The Author(s). 2021 Open Access This article is licensed under a Creative Commons Attribution 4.0 International License, which permits use, sharing, adaptation, distribution and reproduction in any medium or format, as long as you give appropriate credit to the original author(s) and the source, provide a link to the Creative Commons licence, and indicate if changes were made. The images or other third party material in this article are included in the article's Creative Commons licence, unless indicated otherwise in a credit line to the material. If material is not included in the article's Creative Commons licence and your intended use is not permitted by statutory regulation or exceeds the permitted use, you will need to obtain permission directly from the copyright holder. To view a copy of this licence, visit http://creativecommons.org/licenses/by/4.0/. 


\section{Background}

The global mean temperature has risen by approximately $0.85{ }^{\circ} \mathrm{C}$ over the last 130 years, and warming has increased the frequency, intensity, and amount of heavy precipitation events at the global scale (National Institute of Meteorological Sciences 2019). Species faced with climate change respond in several different ways (e.g., geological range changes and phenological shifts) through speciesspecific physiological thresholds of temperature and precipitation tolerance (Pacifici et al. 2019; Wiens 2016). To understand the changes that have already occurred, more large-scale and long-term data are required (Urban et al. 2016). However, baseline data about our ecosystems is generally lacking, which makes it difficult to recognize changes and detect early warning signs (Baker et al. 2016; Shin et al. 2021).

Citizen science (hereafter CS), defined as the participation of the general public in scientific research, has become a mainstream approach to the collection of baseline data in ecology and environmental science (Dickinson et al. 2012). Citizen scientists are compiling vast datasets of contemporary biodiversity and environmental records, and thus CS monitoring can help collect large volumes of observation data for various species over a wide range within an entire country (Pocock et al. 2018). In addition, recent advances in IT technologies have permitted recording using web portals and mobile apps and have supported a vast growth in the recording by citizen scientists across time and space (Ožana et al. 2019). Many CS projects have been conducted and are deemed powerful ways to generate ecological knowledge, stimulate inquiry, provide place-based nature experiences for the public, and gather important baseline data (Cox et al. 2015; Pecl et al. 2019). Observation data by citizen scientists have also contributed extensively to scientific research on distributions related to climate change (Suzuki-Ohno et al. 2017), phenological change (Fuccillo et al. 2014), morphological variation (Moore et al. 2021), and species distribution modeling (Wang et al. 2018), as evidenced by many journal articles.

In South Korea, as a citizen science project, the "Korean Biodiversity Observation Network (hereafter KBON)" has been operated by the National Institute of Biological Resources since 2011. Civic organizations and citizen scientists in the K-BON observe the surrounding biodiversity and record their information (i.e., date, species name, geological location, and photos) using the citizen science platform NATURING (http://www. naturing.net/). In particular, they are focusing on Climate-sensitive Biological Indicator Species (hereafter CBIS). Using this list, the citizen scientists collect data to help predict biodiversity distribution shifts due to climate change and guide to comprehensive management of biological resources at the national level (Lee et al.
2010; National Institute of Biological Resources 2019). Today, the quantity of monitoring data by citizen scientists from K-BON project is growing (National Institute of Biological Resources 2020), and this is expected to enhance our understanding of the impact of biological responses to climate change. However, CS monitoring data has rarely been used for scientific research and policy development in South Korea.

In this study, we selected a damselfly Ischnura senegalensis Rambur (Odonata: Coenagrionidae) as the subject species to examine whether species distribution responses to climate change could be detected using CS monitoring data. This species is widespread in tropical and subtropical parts of the Old World, extending from Africa to Japan at about $35^{\circ} \mathrm{N}$ (Askew 2004; Sharma and Clausnitzer 2016). In South Korea, I. senegalensis was first recorded by Ishida (1969) without giving an exact locality (Yum 2000), and it occurs in the southern provinces including Daejeon, Jeollabuk-do, Jeollanam-do, Gyeongsangnam-do, and Juju-do (Jung 2007; Yum et al. 2010). Dragonflies and damselflies are an important component of aquatic ecosystems and, as highly mobile insects, can colonize suitable habitats rapidly over long distances (Corbet 1993; Balzan 2012). Their mobility and sensitivity to environmental conditions mean that this group is given the highest priority in biodiversity monitoring for global warming (Hassall and Thompson 2008; Termaat et al. 2019; Cerini et al. 2020). Ischnura senegalensis Rambur has been designated as a Korean CBIS and is being monitored by citizen scientists participating in $\mathrm{K}-\mathrm{BON}$ at the national level (National Institute of Biological Resources 2017). In South Korea, the annual mean temperature over the last 40 years (1980-2019) has increased by $1.4{ }^{\circ} \mathrm{C}$, exceeding the global average rate (Moon et al. 2020). Rising temperature has already induced shifts in insect taxa distribution range in South Korea (Kwon et al. 2014; Lee et al. 2020). For example, 10 Korean southern butterfly species have shifted their ranges northwards $(1.6 \mathrm{~km} /$ year $)$ during the last 60 years (Kwon et al. 2014). Ischnura senegalensis Rambur, an insect with a southern distribution in South Korea, is expected to shift its distribution range due to recent climate warming because it is better adapted to warmer conditions. However, this species' distributional responses to changing climate conditions have not previously been examined.

Our study was conducted as follows. First, we collected as many records of I. senegalensis's occurrence from citizen science and other documented data as possible. Second, we assessed trends in the species' distribution range over the past decades from combined datasets. Finally, we predicted the most critical factors affecting the distribution and potential habitat under current and future climate conditions using a species 
distribution model (SDM). Our results should provide the groundwork necessary to understand the distributional response of $I$. senegalensis to changing climate conditions and give new insights into the application of citizen science as a critical data source in scientific research.

\section{Materials and methods}

\section{Data collection and validation}

We collected occurrence records for I. senegalensis from preserved specimens, the National Ecosystem Survey (hereafter NES), and CS. Here, we selected only records of adult individuals and not records of larval stages because closely related species are difficult to distinguish in the larval forms. Occurrence records were extracted from the database for specimens deposited in the National Institute of Biological Resources Herbarium (https://species.nibr.go.kr/). Several older specimens had no GPS data, and thus we converted the address in the text into latitude and longitude data using Google Maps (https://www.google.com/maps). Dataset of NES received data for the $2^{\text {nd }}(1997-2005), 3^{\text {rd }}(2006-2013), 4^{\text {th }}$ (2014-2018), and $5^{\text {th }}$ (2019) from National Ecosystem Institute. The CS dataset comprised records from citizen scientists participating in the K-BON and public participants of the citizen science platform NATURING. To estimate I. senegalensis distributions from CS monitoring, it was essential to obtain accurate species distribution data. Thus, we selected only data with geotagged photographs from the NATURING platform and followed the validation procedure of species identification by experts. To determine shifts in the distribution range of I. senegalensis, we made use of four time periods (1980-2000, 20012010, 2011-2015, and 2016-2020), considering the number of records and the apparent distribution changes. All records were mapped according to the WGS84 coordinate system using the ArcMAP 10.0 geographical information software package.

\section{Environmental variables}

To determine the environmental variables affecting the current I. senegalensis distribution, 19 bioclimatic variables (Hijmans et al. 2005) were calculated from meteorological observation data from the last 10 years (2009-2018) collected by the Korea Meteorological Administration. These variables (Bio1-Bio19) represent annual trends (e.g., mean annual temperature and precipitation), seasonality (annual ranges of temperature and precipitation), and extreme or limiting environmental factors (temperatures of the coldest and warmest months, and precipitation in the wettest and driest quarters). Bioclimatic variables are spatially correlated, which can result in model over-fitting when simulating a species' potential distribution (Thapa et al. 2018). To reduce multi-collinearity among the variables, highly correlated variables (Pearson's correlation coefficient $r>$ $|0.9|)$ were excluded from the modeling process. Ultimately, we selected 10 bioclimatic variables (Bio1, 2, 3, 5, 7, 12, 13, 14,15 , and 16) in this study (Table 1). Future climate data were derived from the MME5s (Multi-Model Ensemble, http://www.climate.go.kr), which is assembled from the Regional Climate Models (RCMs) including HadGEM3-RA

Table 1 Number of occurrence data available for Ischnura senegalensis Rambur in each region according to data source and period in South Korea. NES, National Ecosystem Survey; and CS, Citizen Science

\begin{tabular}{|c|c|c|c|c|c|c|c|c|c|c|c|c|}
\hline \multirow[t]{3}{*}{ Region } & \multicolumn{12}{|c|}{ Period/Source } \\
\hline & \multicolumn{3}{|l|}{$1980-2000$} & \multicolumn{3}{|l|}{ 2001-2010 } & \multicolumn{3}{|l|}{ 2011-2015 } & \multicolumn{3}{|l|}{ 2016-2020 } \\
\hline & Specimen & NES & CS & Specimen & NES & CS & Specimen & NES & $\mathrm{CS}$ & Specimen & NES & CS \\
\hline Gyeonggi-do (Northern) & & & & & & & & & & & & 2 \\
\hline Seoul & & & & & & & & & & & & 5 \\
\hline Incheon & & & & & & & & & & & & 2 \\
\hline Gangwon-do (Wonju) & & & & & & & & & 3 & & & 8 \\
\hline Gyeonggi-do (Southern) & & & & & & & 2 & & 2 & & 3 & 12 \\
\hline Chungcheongbuk-do & & & & & & & 1 & 1 & 1 & 1 & 3 & 3 \\
\hline Chungcheongnam-do & & & & 1 & & 1 & & & 15 & 6 & 1 & 27 \\
\hline Gyeongsangbuk-do & & & & & & 1 & 1 & 2 & & 5 & 8 & 7 \\
\hline Jeollabuk-do & & & & 1 & & 2 & & 6 & 12 & 3 & 3 & 14 \\
\hline Gyeongsangnam-do & 6 & & & 2 & & 4 & 3 & & 4 & 3 & 4 & 43 \\
\hline Jeollanam-do & 4 & & & & & 3 & 21 & 5 & 19 & 5 & 36 & 25 \\
\hline Jeju-do & & & & 3 & & 4 & 1 & & 5 & 19 & 4 & 9 \\
\hline Total & 10 & - & - & 7 & - & 15 & 29 & 14 & 61 & 42 & 62 & 157 \\
\hline
\end{tabular}

Daejeon was included in Chungcheongnam-do; Daegu and Ulsan were included in Gyeongsangbuk-do; Busan and Ulsan were included in Gyeongsangnam-do; Gwangju was included in Jeollanam-do 
(Hadley Centre Global Environmental Model version 3 Regional Atmosphere), RegCM4 (The Regional Climate Model version 4), SNURCM (Seoul National University Regional Climate Model), GRIMs (Global/Regional Integrated Model System), and WRF (Weather Research and Forecasting) developed by National Institute of Meteorological Sciences (Jeju-do, Republic of Korea). To predict the potential distribution of I. senegalensis under future climate condition, climate data sets for RCP4.5 (Medium: $\mathrm{Wm}^{-2}$, 650 ppm $\mathrm{CO}_{2}$ ) climate scenario (van Vuuren et al. 2011) in the 2050s (average for 2041-2060) and 2070s (average for 2061-2080) were used. The RCP4.5 scenario is described by the IPCC as an intermediate scenario. All data had a spatial resolution of 30 arc-seconds (approx. $853 \mathrm{~m}$ at the Korean Peninsula).

\section{Species distribution modeling}

To develop the species distribution model for I. senegalensis, we performed proper treatment on the occurrence dataset to avoid noise and spurious correlations (La Sorte et al. 2018) in the results. We removed duplicate records, coincident records in the defined grid cell (about $853 \times 853 \mathrm{~m}$ ), and the latest records (in the metropolitan region during 2019-2020) from our dataset. After this filtering, we obtained 260 points for distribution model estimates of I. senegalensis.

Species distribution models were created using MaxEnt software v. 3.4.1 (www.cs.princeton.edu/"schapire/ maxent/). This is one of the best distribution model techniques using presence-only data and is widely used to predict the distribution of many taxa, including insect species (Lancaster et al. 2015). Model performance was evaluated with the area under the curve (AUC) values of the receiver operating characteristics (ROC) curves (Lobo et al. 2008). The AUC values below 0.7 were considered poor, values between 0.7 and 0.8 were fair, values between 0.8 and 0.9 were good, and those above 0.9 were considered excellent (Phillips et al. 2006). We performed 10 random runs and selected $70 \%$ of the data for model training and 30\% for model testing, keeping other values as defaults. The final potential species distribution map had a range of values from 0 to 1 , which were reclassified into four categories of habitat suitability for I. senegalensis: "high potential" (> $0.6)$, "moderate potential" (0.4-0.6), and "low potential" $(0.2-0.4)$ and "not potential" $(<0.2)$.

\section{Results}

Records of $I$. senegalensis occurrence

In this study, we constructed a dataset for a total of 397 records with $I$. senegalensis occurrence in South Korea from 1980 to 2020 (see Additional file 1). During 19802000, records were collected only from specimens (Fig. 1). Since then, the number of records from specimen data has steadily increased, with a total of 88 records for the entire period (Table 1; Fig. 2A). The National Ecosystem Survey data was recorded for the first time in 2012, and since then, it has rapidly increased, with a total of 76 records (Table 1; Fig. 2B). Occurrence data have been collected by citizen scientists since 2003, and this category with a total of 233 observations occupied the largest proportion of the I. senegalensis distribution dataset, accounting for $58.7 \%$ of the total records (Table 1; Fig. 2C). The number of $I$. senegalensis occurrence records has increased over time, and records during the last 5 years

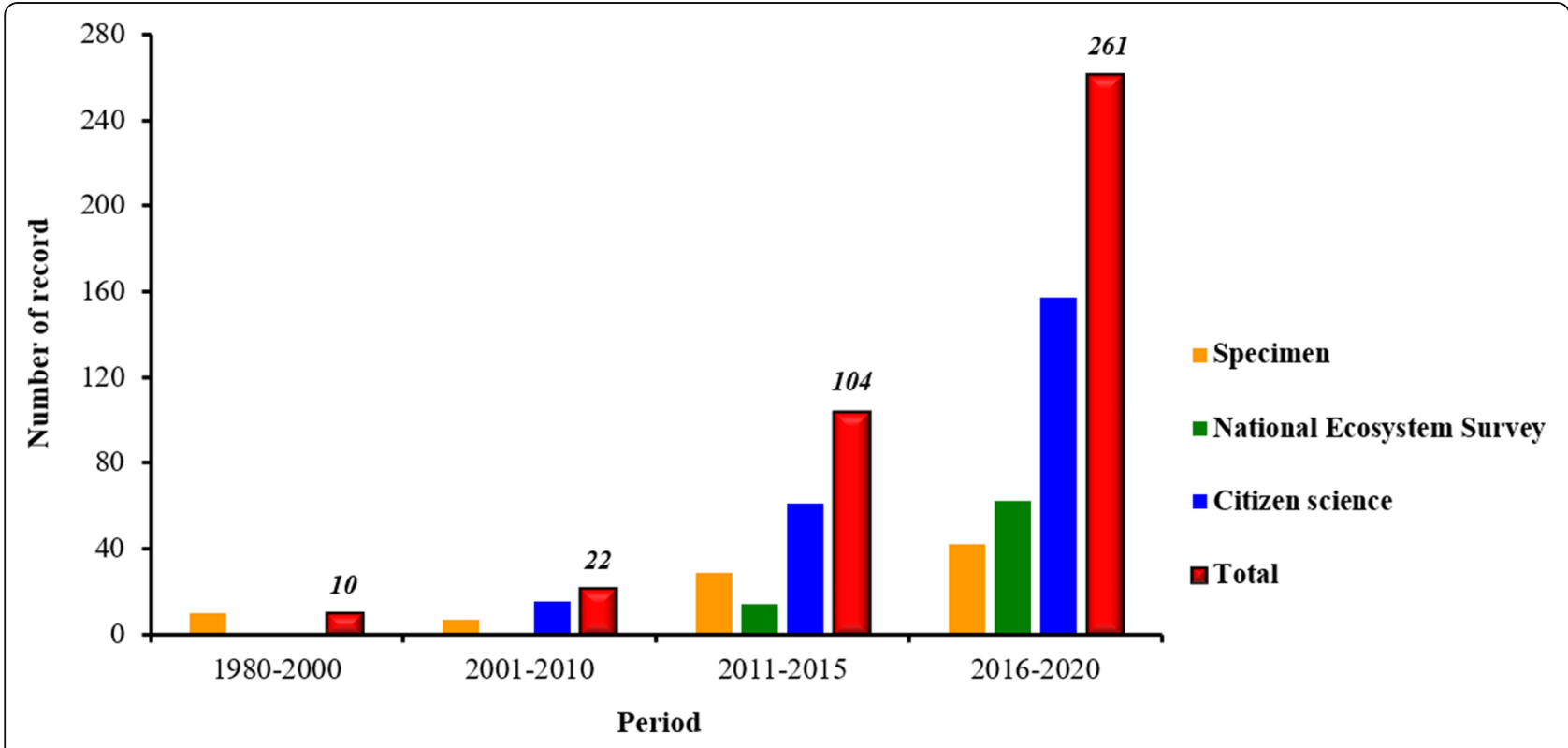

Fig. 1 Changes in the number of records for Ischnura senegalensis Rambur occurrence in each data source in relation to time 


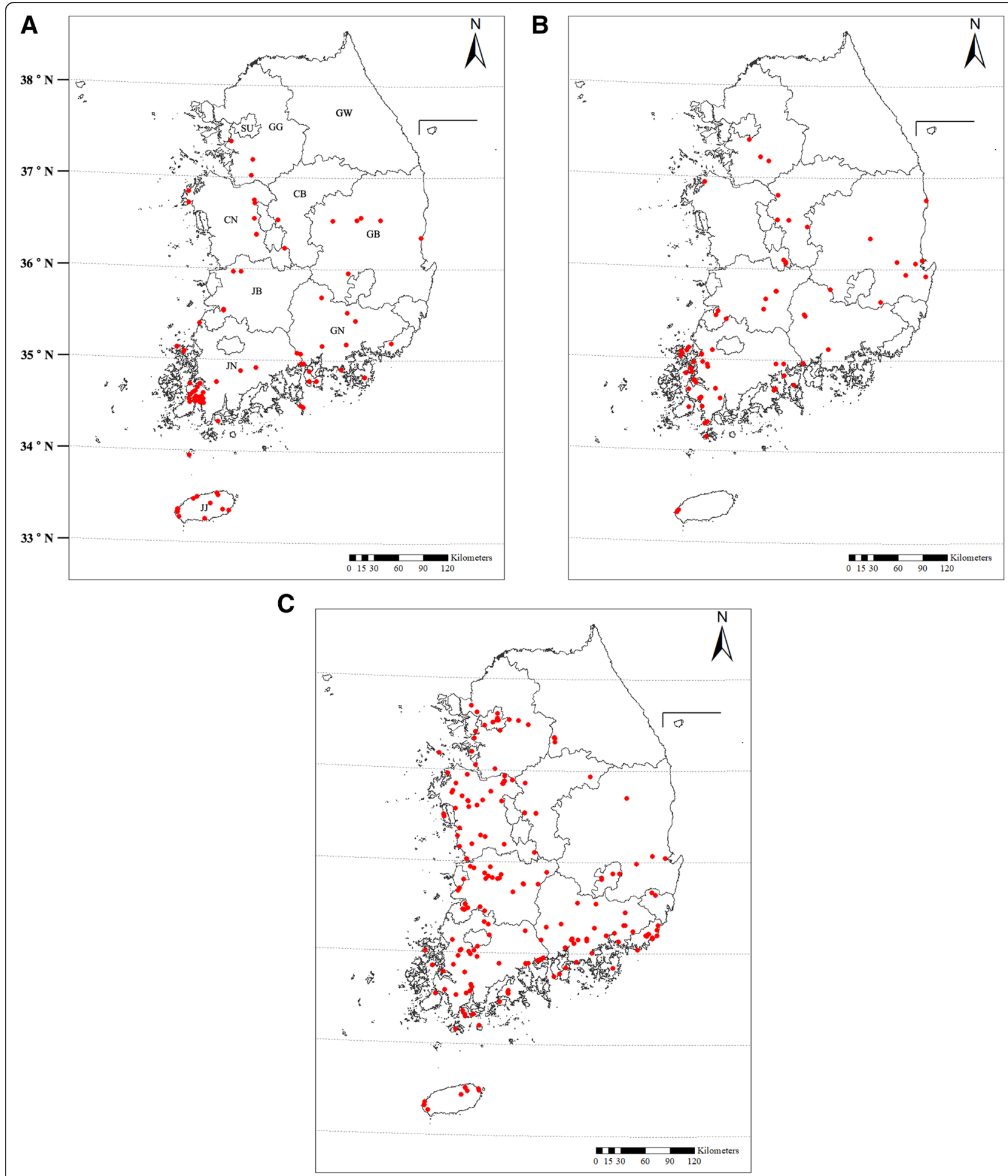

Fig. 2 Distribution maps of Ischnura senegalensis Rambur based on each data source. A Specimen $(n=88)$, B National Ecosystem Survey $(n=76)$, and C Citizen science ( $n=233$ ). GG Gyeonggi-do, SU Seoul, GW Gangwon-do, CB Chungcheongbuk-do, CN Chungcheongnam-do, GB Gyeongsangbuk-do, GN Gyeongsangnam-do, JB Jeollabuk-do, JN Jeollanam-do, JJ Jeju-do

(2016-2020) were two times more than the total of those of the three previous periods (1980-2000, 2001-2010, and 2011-2015).
Northward shifts in distribution range of $I$. senegalensis The first record of I. senegalensis in South Korea based on our dataset was confirmed in Hadong-gun, 
Gyeongsangnam-do in 1980 (Additional file 1). From 1980 to 2000, the species was only recorded on the parts of the coast of the Jeollanam-do and Gyeongsangnam-do that were below $36^{\circ}$ in latitude (Table 1; Fig. 3A). Since then, individuals have been recorded in higher latitude regions in Jeollabuk-do and Chungcheongnam-do and the southern provinces (Table 1; Fig. 3B). Until 2010, this species was recorded only below $37^{\circ}$ latitude, and the northern limit was Seosan-si, Chungcheongnam-do (36.71 ${ }^{\circ}$ latitude).

From 2011 to 2015, records of the occurrence of $I$. senegalensis in the southern provinces increased, and the species even appeared in parts of southern Gyeonggi-do and Gangwon-do, expanding the distribution range to higher latitudes (Table 1; Fig. 3C). In 2014, I. senegalensis was first recorded in Yangpyeong-gun, southern Gyeonggi-do, and Wonju-si, Gangwon-do by citizen scientists (Fig. 4). Moreover, in 2015, specimen data also showed occurrences in Siheung-si and Osan-si, southern Gyeonggi-do. Until 2015, the northern limit region of $I$. senegalensis occurrence was Yangpyeong-gun, southern Gyeonggi-do (37.50 latitude).

Between 2016 and 2020, the distribution range of $I$. senegalensis expanded across the country except for the higher latitudes in some parts of northern Gyeonggi-do and Gangwon-do (Table 1; Fig. 3D). Occurrence records increased more in the southern provinces than during previous periods. Some striking changes during this period included the first records of $I$. senegalensis in Seoul, Incheon, and northern Gyeonggi-do at higher latitudes (Fig. 4). In 2016, I. senegalensis was first recorded in Seoul (Seoul Forest Park), and in 2018, it was first recorded in Incheon (Sorae-Wetland). After that, the distribution range expanded even more toward higher latitudes, and the species was first recorded in Goyang-si (Janghang-Wetland) of northern Gyeonggi-do in 2019 and Paju-si in 2020.

\section{Climatic variables affecting the spatial distribution}

Our resulting SDM had an AUC of $0.80 \pm 0.02$, indicating a good model fit to the data. The relative contributions of each environmental variable to the model are shown in Table 2. Among the climatic variables, the annual mean temperature (Bio1) and the maximum temperature of the warmest month (Bio5) contributed a total of $79.9 \%$ of habitat suitability. Biol was the best predictor of habitat suitability in our SDM, explaining the greater proportion $(63.2 \%)$ of the variation in habitat suitability for I. senegalensis. In contrast, precipitationrelated variables only contributed $7.4 \%$.

Species response curves represent the relationships between the probability of I. senegalensis occurrence and environmental variables. According to the response curves for the two largest contributing climatic variables, the range of Bio1 for I. senegalensis ranged from 6.0 to $16.0^{\circ} \mathrm{C}$, and Bio5 was $23.0-32.0^{\circ} \mathrm{C}$ (Fig. 5). Habitat suitability of $I$. senegalensis increased with higher values of Bio 1 and Bio5. In particular, this species preferred habitats with Bio1 above about $13.5{ }^{\circ} \mathrm{C}$ and Bio5 above about $30.0{ }^{\circ} \mathrm{C}$ (probability of presence $>0.6$ ).

\section{Potential habitat under current and future climate conditions}

The model showed that the western and the southern provinces have favorable environmental habitats for $I$. senegalensis based on current climate and occurrence data (Fig. 6A). Currently, highly suitable habitats occur along the coastal areas of Jeollanam-do, Gyeongsangnam-do, and Jeju Island. The potential distribution under future climate conditions is predicted to increase relative to the suitable distribution under the current climate conditions. In the 2050s, the suitable habitat for I. senegalensis is predicted to expand to all areas except several parts of northern Gyeonggi-do and the mountain areas of Gangwon-do (Fig. 6B). In particular, the increase in highly suitable habitats is particularly significant in the western and eastern coastal regions, the southern provinces, Jeju-do Island, and Ulleng-do Island. In the 2070s, the suitable habitat for I. senegalensis will be even more extensive than under current conditions and in the 2050s (Fig. 6C). In the future, the area of habitat with high potential will expand toward higher latitudes in South Korea.

\section{Discussion}

This is the first study to reveal the distribution range shifts of I. senegalensis toward higher latitudes between 1980 and 2020 in South Korea. Records across time and space give an overview of $I$. senegalensis distribution under current conditions. Our results show that this species has consistently adapted to warmer climates and is rapidly expanding its geographic range northward in response to warming trends.

\section{Combined distribution dataset covering temporal and spatial gaps}

The number of I. senegalensis occurrence records has increased over time (Fig. 1), and the species' geographic range has also expanded (Fig. 3). An important concern about studies on climate-induced range expansions is that simply the outcome of a higher number of records in the following observation period (Grew et al. 2013). Also, data derived from opportunistic observations rather than planned surveys often exhibit a strong geographic bias because some areas may be visited more often than others due to their accessibility or their natural history interest (Fourcade et al. 2014; Rapacciuolo et al. 2017). Combining data from different approaches 


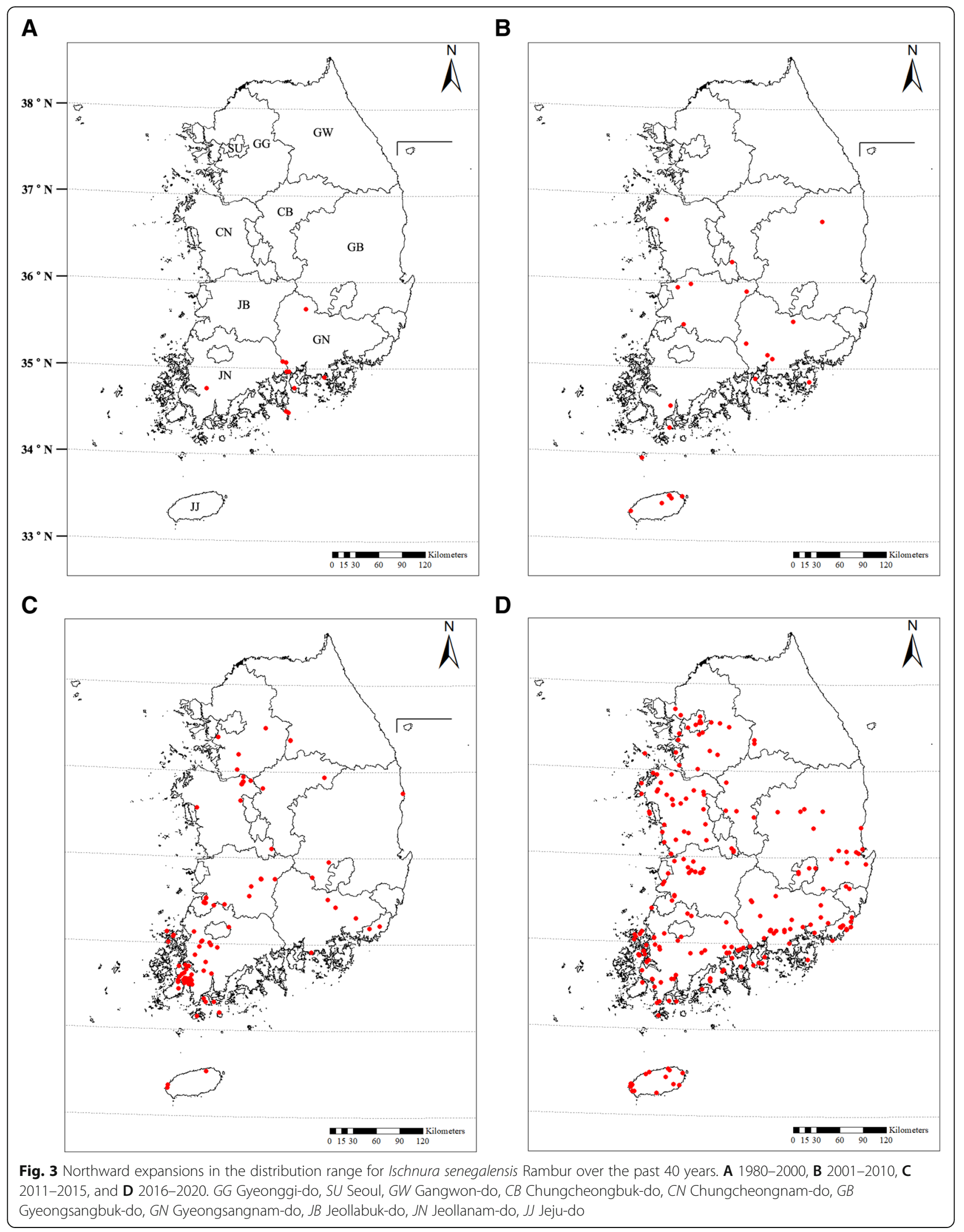




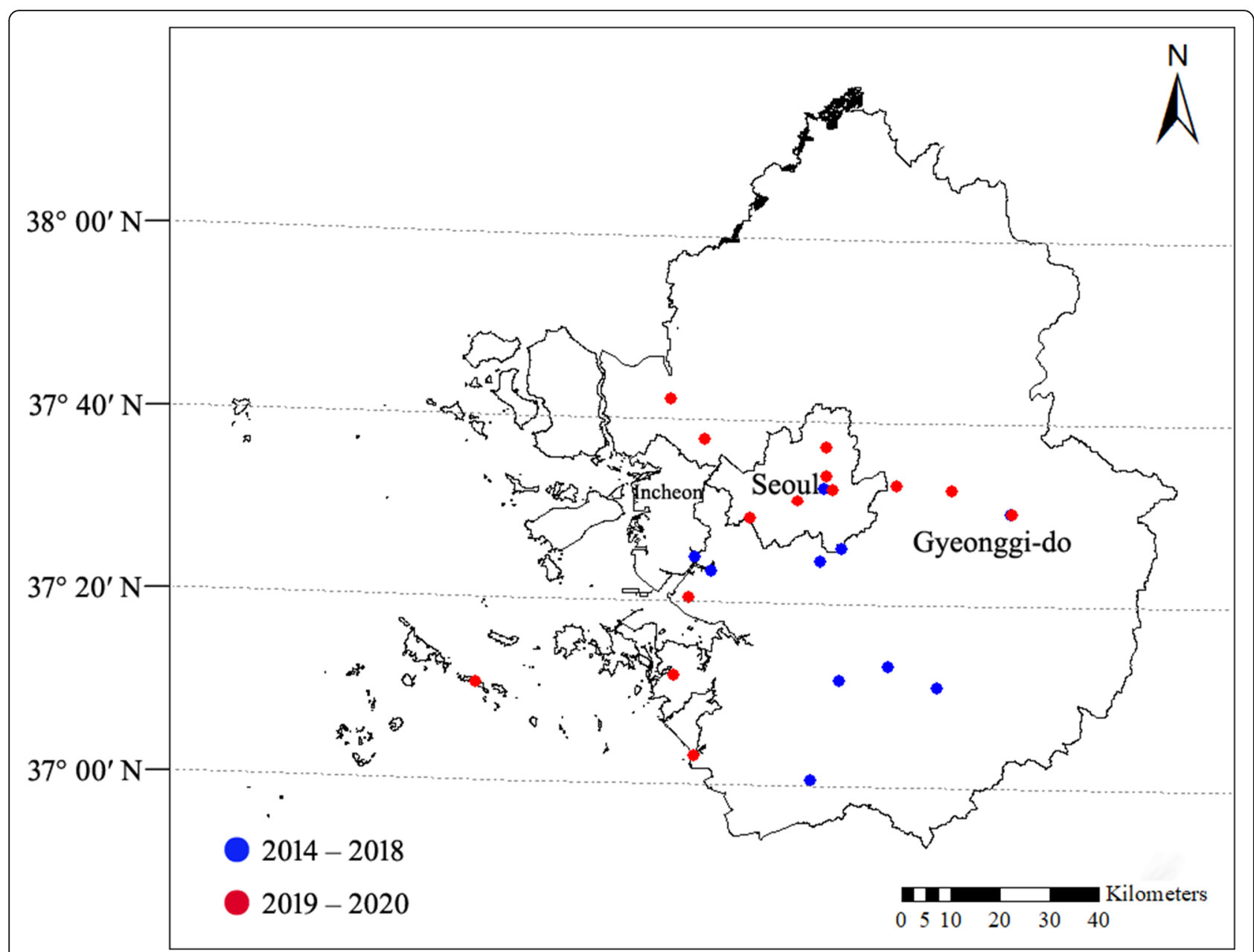

Fig. 4 Distribution shifts toward higher latitudes of Ischnura senegalensis Rambur in the metropolitan region over the past seven years (2014-2020)

Table 2 Bioclimatic variables and their percentage contribution in predicting the potential distribution of Ischnura senegalensis Rambur. The most important variables are highlighted in bold

\begin{tabular}{lll}
\hline Variable code & Description (Unit) & Contribution (\%) \\
\hline Bio1 & Annual mean temperature $\left({ }^{\circ} \mathrm{C}\right)$ & $\mathbf{6 3 . 2}$ \\
Bio2 & Annual mean diurnal range $\left({ }^{\circ} \mathrm{C}\right)$ & 5.4 \\
Bio3 & Isothermality $\{($ Bio2/Bio7) $\times 100\}(\%)$ & 4.2 \\
Bio5 & Max temperature of warmest month $\left({ }^{\circ} \mathrm{C}\right)$ & $\mathbf{1 6 . 7}$ \\
Bio7 & Annual temperature range $($ Bio5 - Bio6 $)\left({ }^{\circ} \mathrm{C}\right)$ & 2.8 \\
Bio12 & Annual precipitation $(\mathrm{mm})$ & 0.9 \\
Bio13 & Precipitation of wettest month $(\mathrm{mm})$ & 1.1 \\
Bio14 & Precipitation of driest month $(\mathrm{mm})$ & 2.2 \\
Bio15 & Precipitation seasonality $(\%)$ & 1.5 \\
Bio16 & Precipitation of wettest quarter $(\mathrm{mm})$ & 1.7 \\
\hline
\end{tabular}



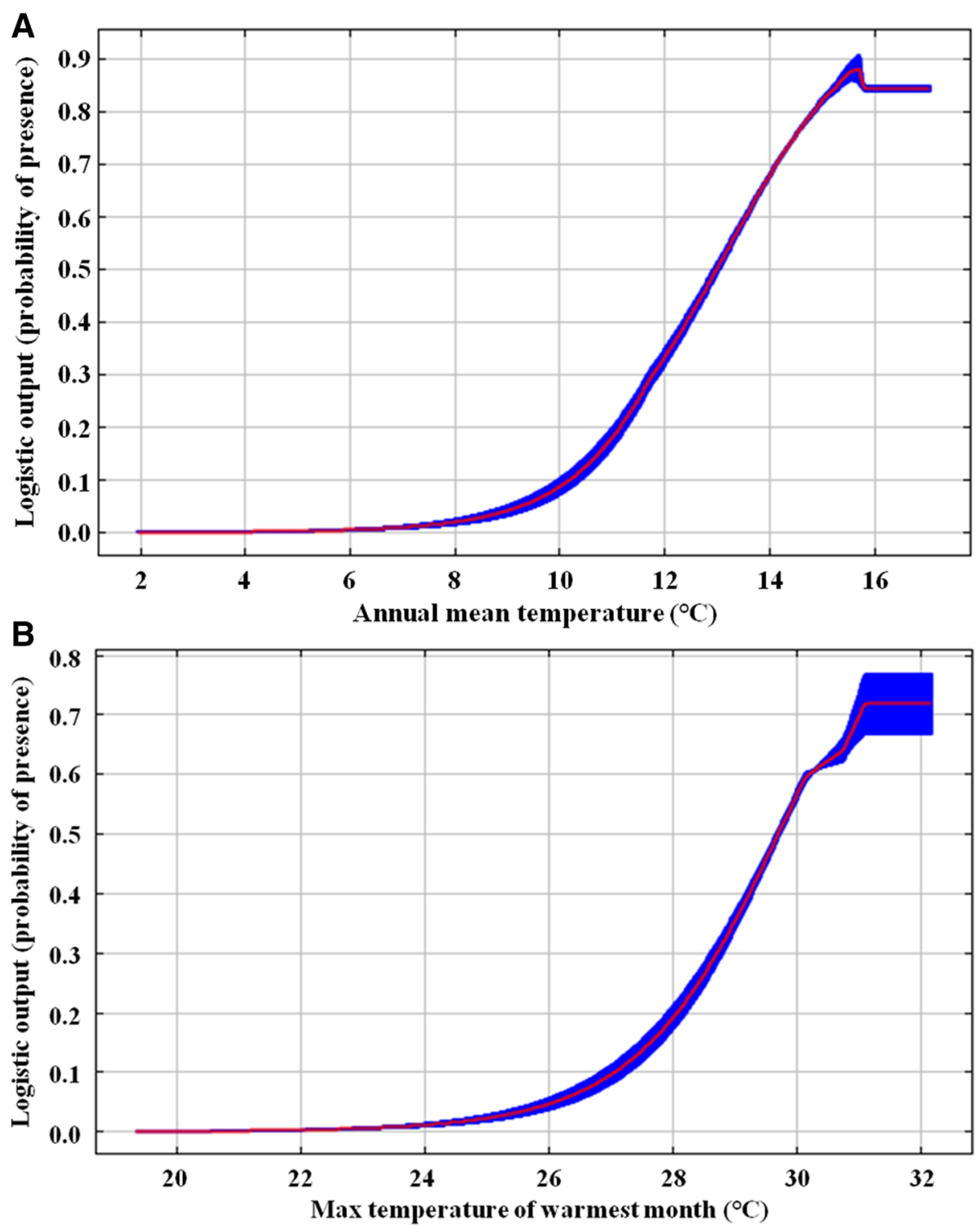

Fig. 5 The response curves for the two largest contributing climatic variables for Ischnura senegalensis Rambur under current climate conditions. Response curves indicate the correlation between the climatic variables used for prediction and the probability of the presence of Ischnura senegalensis Rambur

could mitigate these problems (Hassall and Thompson 2008; Silvertown 2009; Roy-Dufresne et al. 2019).

In this study, we constructed a combined dataset on the distribution of I. senegalensis from specimens, NES and CS. The historical records (1980-2002) were available only from specimen data, and they only provided information on the past distribution range of I. senegalensis in the southern provinces (Table 1). Scientific research on shifts in species' distribution range requires defect information that was not previously distributed in the current distribution range (Suzuki-Ohno et al. 2017). The NES generates baseline data from a law-bound, nationwide, multidisciplinary project that provides biodiversity status at survey points across the country (Kim et al. 2013). In the $3^{\text {rd }}$ NES, for example, I. senegalensis was recorded at only three points in Jeollanamdo (Yeongam, Jindo, and Haenam) among the surveyed 17 provinces or cities. Data from the NES addressed concerns about opportunistic observations through monitoring at survey points across the country. In addition, CS data contained the largest proportion of records $(58.7 \%$ of the dataset) and the widest geographical range (Table 1; Fig. 2C). Thus, a combined dataset enables complementary coverage in temporal and spatial gaps, which successfully contributes to the detection of species distribution shifts over time. 


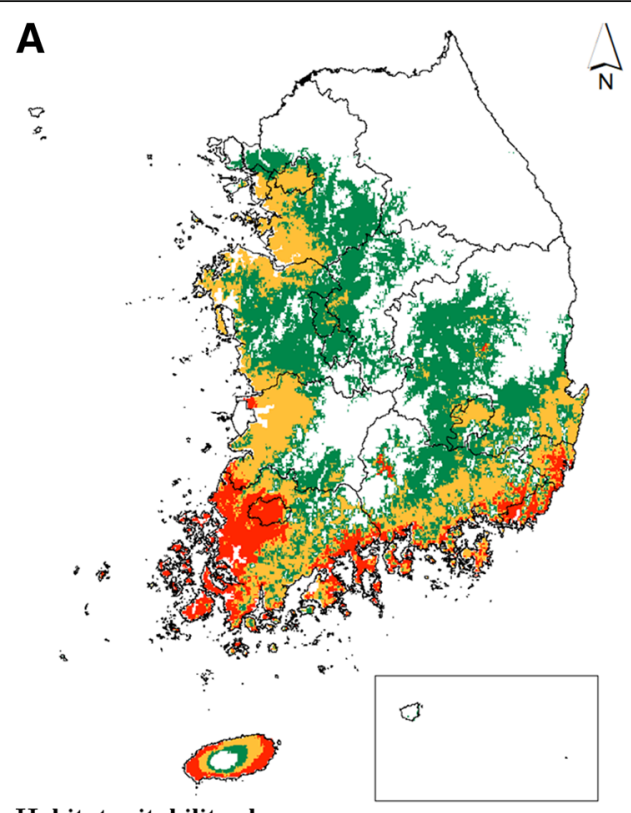

Habitat suitability classes

\section{$\square$ Not potential $(<0.2)$}

Low potential $(0.2-0.4)$

B

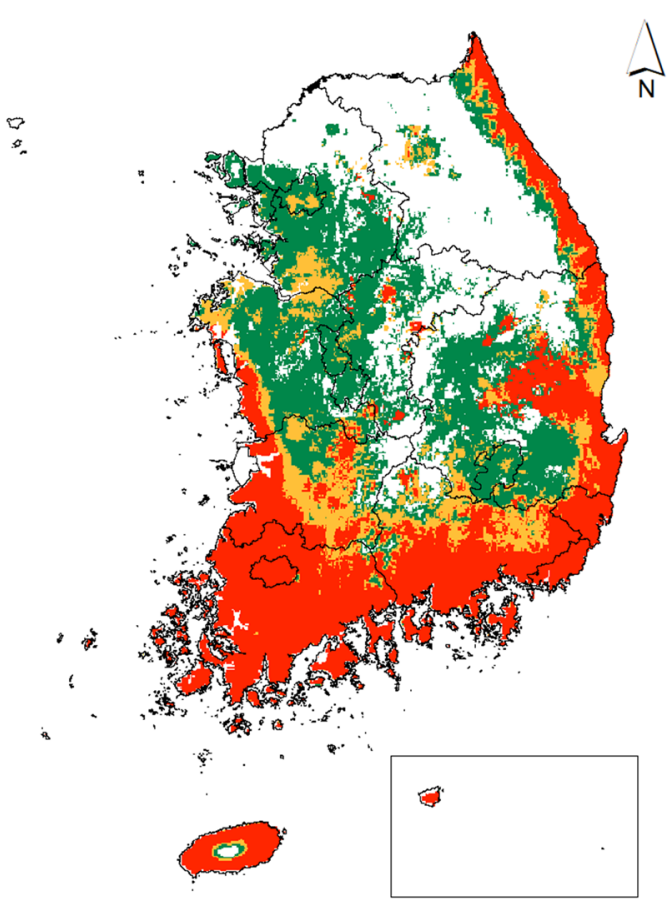

High potential $(>0.6)$
C

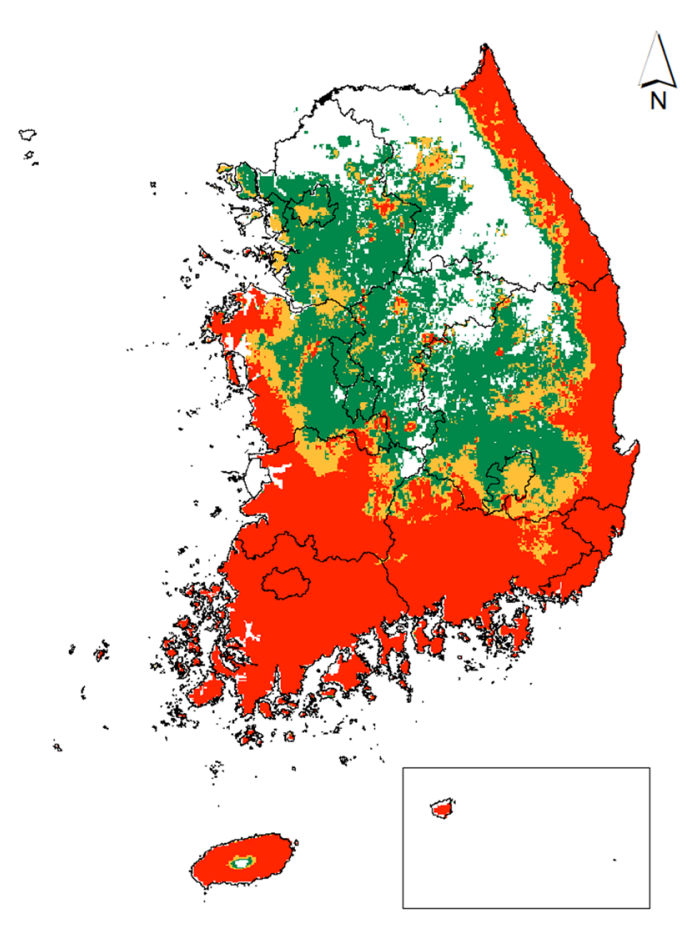

Fig. 6 The potential distribution of Ischnura senegalensis Rambur under current and future climatic conditions based on RCP 4.5 scenarios. A Current, B 2050s, and C 2070s 


\section{Citizen science as a critical tool in detecting distributional responses to climate change}

Citizen science has become a mainstream method for gathering baseline data by enabling the collection of greater numbers of records over longer periods and broader spatial scales than would otherwise be possible. In addition, it can be effective even in traditionally datapoor areas (Pocock et al. 2018; Pecl et al. 2019). Our study revealed the critical role of CS in identifying the distribution range of I. senegalensis. Notably, the first records of $I$. senegalensis in the metropolitan region (Gyeonggi-do, Seoul, and Incheon) and Gangwon-do (Wonju-si), which had not yet been documented in the scientific literature, were revealed through CS monitoring (Table 1). Although sampling bias is often mentioned as a problem in outcomes from CS monitoring (Bird et al. 2014), in our study, CS data showed the widest geographic range and covered all the distribution points of the specimen and NES data (Fig. 2). The broad geographic coverage of CS data was possible because the $\mathrm{K}-\mathrm{BON}$ project is a nationwide monitoring exercise by citizen scientists. In addition, the CS recorders generated 1.4 times as much as data in specimen $(n=88)$ and NES $(n=76)$. Numerous records by citizen scientists were possible because I. senegalensis was designated as CBIS, i.e., a biological indicator sensitive to climate change (National Institute of Biological Resources 2017), which enabled intensive monitoring. Recording using the web portal and mobile app of NATURING also contributed to the increase in the recording by citizen scientists across time and space. As a result, the CS dataset with its greater numbers and broader spatial scales has become the most powerful tool to reveal the distributional shifts of $I$. senegalensis in South Korea in response to climate change.

Although CS has great potential to gather information on a wide temporal and spatial scale, the accuracy of the data is often a matter of concern (Bird et al. 2014; Suzuki-Ohno et al. 2017). Thus, we designed approaches to increase the accuracy of data collected through CS monitoring. In general, data compiled by participants who have been involved for longer periods, participants who had training, and larger groups are more accurate (Aceves-Bueno et al. 2017). In our datasets, most of the CS data were collected from observations of citizen scientists belonging to the $\mathrm{K}-\mathrm{BON}$, in particular, recording by the Odonata Society of Korea as the civil organization participating in the K-BON. Operators of $\mathrm{K}-\mathrm{BON}$ also provide a standard protocol, participant training, crosschecking, and validation of observations to ensure highquality data (National Institute of Biological Resources 2020). Therefore, CS data collected from the K-BON consists of records by professional citizen scientists with specific scientific training rather than records gathered through public participation. In addition, we selected only records with geo-tagged photographs from the citizen science platform NATURING because we could identify the species correctly using photographic images as long as they included the characters necessary for identification and could extract the correct location of a species' observation from the GPS data. We subjected monitoring records (including geo-tagged photographs uploaded in NATURING) to identification procedures by experts and used only verified CS records. These approaches guaranteed the high quality of the CS data included in our study.

\section{Warming-induced northward range expansion}

Most species are adapted to particular temperature ranges, and temperature is often a major environmental factor influencing their distribution (Suhling et al. 2015; Moore et al. 2021). One of the most distinctive responses in species facing climate change is the poleward and/or the upward shift of distribution ranges associated with warming temperatures (Parmesan and Yohe 2003; VanDerWal et al. 2012). Climate-mediated range shifts in Odonata are well documented (Hickling et al. 2005; Grewe et al. 2013; Termaat et al. 2019). For example, 37 British Odonata species have shifted northwards at their range margins over the past 40 years (Hickling et al. 2005). Our study also highlighted the northward expansion of I. senegalensis in South Korea between 1980 and 2020 (Fig. 3). Understanding how species ranges have responded to changing climate and predicting how these responses will be manifest in the future requires knowledge of the mechanisms that determine the realized niche (Grewe et al. 2013). Thus, we developed a distribution model for $I$. senegalensis, and this model showed that temperature-related variables (i.e., annual mean temperature and maximum temperature of the warmest month) are the most important factors affecting the geographic distribution of I. senegalensis (Table 2).

We found that $I$. senegalensis preferred warmer habitats with the annual mean temperature (Bio1) above about $13.5{ }^{\circ} \mathrm{C}$ and the maximum temperature of the warmest month (Bio5) above about $30.0^{\circ} \mathrm{C}$ (Fig. 5). The annual mean temperatures during 1980-2000 were measured at $14.1{ }^{\circ} \mathrm{C}$ and $13.3{ }^{\circ} \mathrm{C}$ in Gyeongsangnam-do (Namhae-gun, $34.8^{\circ} \mathrm{N}$ ) and Jeollanam-do (Haenam-gun, $34.6^{\circ} \mathrm{N}$ ), respectively, both being areas where I. senegalensis occurred. During the same period, the annual mean temperatures in Chungcheongnam-do (Seosan-si, $36.8^{\circ} \mathrm{N}$ ) and southern Gyeonggi-do (Yangpyeong-gun, $37.5^{\circ} \mathrm{N}$ ), which are higher latitudinal regions with no records for I. senegalensis, were $11.7{ }^{\circ} \mathrm{C}$ and $10.8{ }^{\circ} \mathrm{C}$, respectively, below the temperature of the species' preferred habitat. The rate of warming has accelerated since the mid-2010s, and temperature increase trends in 
central Korea (i.e., Seoul, Gyeonggi-do, and Gangwon-do) were stronger than those in other regions (Moon et al. 2020). In our study, this period (i.e., the mid-2010s) coincided with the first recordings of $I$. senegalensis in the metropolitan region (Table 1). In particular, Yangpyeonggun in southern Gyeonggi-do is a dragonfly monitoring site that has been observed since 2002 by the Odonata Society of Korea participating in the K-BON, but I. senegalensis was first recorded only in 2014. Since then, records of $I$. senegalensis have increased in the metropolitan region, and the geographic range has expanded to places in higher latitudes such as Seoul, Gangwon-do, Incheon, and northern Gyeonggi-do by 2020 (Table 1; Figs. 3 and 5). In Seoul, in particular, the occurrence of I. senegalensis was first recorded in 2016, and the number and geographical range of records further increased in 2020. The annual mean and maximum temperatures in Seoul over the past 5 years were $13.3^{\circ} \mathrm{C}$ and $31.4{ }^{\circ} \mathrm{C}$, respectively, corresponding to the preferred temperature range for I. senegalensis. In recent years, a rapid temperature rise in the metropolitan region seems to have induced the northward shifts by providing a suitable temperature range for I. senegalensis, which prefers a warmer climate.

Previously documented data showed that I. senegalensis was a Korean insect species found only in the southern provinces and Jeju-do Island (Yum 2000; Jung 2007; Yum et al. 2010). Our study revealed that $I$. senegalensis has now been recorded in all parts of the country except some areas in northern Gyeonggi-do and Gangwon-do (Fig 3D). Ischnura senegalensis is a lentic (standing water) species found in ponds and wetlands, which has higher dispersal ability than lotic (running water) species because of the lower spatial and temporal persistence of lentic habitats (Ribera and Vogler 2000). Grew et al. (Grewe et al. 2013) reported that lentic species of the southern group in Europe expanded their range boundaries on average $115 \mathrm{~km}$ northwards per decade. According to our dataset, the northern range boundary of $I$. senegalensis shifted about $223.8 \mathrm{~km}$ from Geochang-gun, Gyeongsangnam-do (35.7 latitude in 2000) to Paju-si, northern Gyeonggi-do (37. $7^{\circ}$ latitude in 2020). Our results showed climate-induced shifts in the distribution range of $I$. senegalensis and revealed that this species is no longer a Korean southern insect group.

\section{Potential habitat expansion under future climate conditions}

Future climate change is expected to proceed rapidly (Loarie et al. 2009), and the temperature increase in South Korea is projected to be up to $0.63{ }^{\circ} \mathrm{C}$ per decade by the twenty-first century (National Institute of Meteorological Sciences 2019). In addition, the subtropical climate zone is predicted to expand to most of the Korean Peninsula except for some areas of the
Baekdudaegan mountain range with high altitudes by 2100 (Park et al. 2013; Kim et al. 2017). Therefore, future climatic conditions may induce an increase in the occurrence of species preferring warm environments. Many studies using species distribution models have predicted that suitable habitats of Korean southern insect species will expand under future global warming (Kwon 2012; Lee et al. 2015; Kim et al. 2018). For example, Adhikari et al. (2020) reported the northward expansion of the range of eight southern butterflies due to climate change in South Korea. Our model also showed that the distribution range of I. senegalensis would expand in the entire Korean peninsula as temperature rises in the future (Fig. 6). In particular, the increase in distribution ranges appears likely to be more pronounced in the 2070s with higher temperature increases (Fig. 6C). Under RCP4.5 as a stabilization scenario, the annual mean temperature in South Korea is projected to increase from $2.2{ }^{\circ} \mathrm{C}$ (in the 2050s) to $3.6^{\circ} \mathrm{C}$ (in the 2070s) compared with the current conditions. Our projections further indicate that species of southern insects that are adapted to warm weather (Fig. 5) and prefer higher temperatures are likely to expand their ranges as a response to future global warming. Future climate projections consistently predict a temperature rise, and this explains why potentially suitable habitat for I. senegalensis will increase.

Species distribution is affected not only by climaterelated elements but also by more complex environmental factors, including biotic and terrain effects (Leach et al. 2016). However, our model predicted I. senegalensis' future distribution expansion considering only climatic factors. This species is found in wetland habitats such as ponds, lakeshores, and slow-flowing streams (Jung 2007). The environmental disturbance caused by local climate change-related drought and torrential rain negatively affects water quality and diatom communities in rivers. Therefore, it is necessary to examine the effects of local climate changes on the habitat quality of a species. Nevertheless, our findings suggest that distributional shifts could be an important component of future adaptation.

\section{Conclusions}

This study reveals the northward expansion of I. senegalensis in response to climate change in South Korea over the past 40 years. Combined datasets were optimal for detecting shifts in the species' distributional range over time and space; in particular, the CS data expressed the distribution expansion trends in the higher latitudinal metropolitan region. In 2021, the mating of I. senegalensis was observed by citizen scientists of $\mathrm{K}-\mathrm{BON}$ in Dream Forest Park, Seoul. Mating activity indicates that population formation and the overwintering of individuals 
is possible in this area. Therefore, the shifts of I. senegalensis toward higher latitudes can be explained more as a result of species' response to climate change than as an opportunity effect. Our study supports the suitability of dragonfly species as biological indicators of climate change and suggests the advisability of consistent monitoring of the population demography and distribution shifts of $I$. senegalensis under future climate warming. Above all, our study emphasizes that citizen science data can play an important role in monitoring ecosystem impacts on climate change. It is difficult for researchers to collect field data in a timely manner or simultaneously monitor numerous species' responses to climate change. Citizen science engages the public in scientific projects that are challenging for scientists lacking the resources to gather or analyze data on a large scale (Pocock et al. 2018). Moreover, CS is a way to raise societal awareness about the stakes of biodiversity conservation (Lewandowski and Oberhauser 2017). Even now, citizen scientists are observing the biodiversity around them, recording it using web applications, and the records are being shared with everyone in realtime. Researchers may find our experience useful when constructing their own datasets. In the future, it is expected that scientific research using the CS method will further increase and expand to new areas.

\section{Abbreviations}

CBIS: Climate-sensitive Biological Indicator Species; CS: Citizen science; KBON: Korea Biodiversity Observation Network; NES: National Ecosystem Survey; SDM: Species distribution model

\section{Supplementary Information}

The online version contains supplementary material available at https://doi. org/10.1186/s41610-021-00209-7.

Additional file 1. Dataset for Ischnura senegalensis Rambur occurrences during 1980-2020 in South Korea constructed in this study.

\section{Acknowledgements}

We are grateful to many citizen scientists participating in the K-BON, especially Jae Won Jang, Jae Man Kim, Myung Hoe Oh, and Su Hwan Lee of the Odonata Society of Korea who collected the major part of the citizen data used in our study, and all volunteer dragonfly observers of the NATURING. Their monitoring and records made possible the distribution shifts analysis. We also thank anonymous reviewers for helpful comments on the drafts of this article.

\section{Authors' contributions}

SS conceived the ideas, conducted the data collection and analysis, and wrote the manuscript. KSJ conceived the ideas, conducted field study, checked the database, and reviewed the manuscript. HGK conceived the ideas and reviewed the manuscript. JHD and DK conducted the data analysis. JEH reviewed the manuscript. JHK examined the manuscript. All authors read and approved the final manuscript.

\section{Funding}

This work was supported by a grant from the National Institute of Biological Resources (NIBR), funded by the Ministry of Environment (MOE) of the Republic of Korea (NIBR202129101).

\section{Availability of data and materials}

The datasets generated during and/or analyzed during the current study are available from the corresponding author on reasonable request.

\section{Declarations}

Ethics approval and consent to participate

Not applicable.

\section{Consent for publication}

Not applicable.

\section{Competing interests}

The authors declare no competing interests.

\section{Author details}

'Department of Biological Resources Utilization, National Institute of Biological Resources, Incheon 22689, Republic of Korea. ${ }^{2}$ Odonata Society of Korea, Goyang, Republic of Korea. ${ }^{3}$ NATURING, Seoul 04797, Republic of Korea.

Received: 8 November 2021 Accepted: 18 November 2021

Published online: 09 December 2021

\section{References}

Aceves-Bueno E, Adeleye AS, Feraud M, Huang Y, Tao M, Yang Y, et al. The accuracy of citizen science data. Bull Ecol Soc Am. 2017;98(4):278-90. https:// doi.org/10.1002/bes2.1336.

Adhikari P, Jeon J-Y, Kim HW, Oh H-S. Northward range expansion of southern butterflies according to climate change in South Korea. J Clim Chang Res. 2020;11(6-1):643-56. https://doi.org/10.15531/KSCCR.2020.11.6.643.

Askew RR. The dragonflies of Europe. Colchester: Harley Books; 2004. https://doi. org/10.1163/9789004474383.

Baker DJ, Hartley AJ, Butchart SHM, Willis SG. Choice of baseline climate data impacts projected species' responses to climate change. Glob Chan Biol. 2016;22(7):2392-404. https://doi.org/10.1111/gcb.13273.

Balzan MV. Associations of dragonflies (Odonata) to habitat variables within the Maltese Islands: a spatiotemporal approach. J Insect Sci. 2012;12(87):1-18. https://doi.org/10.1673/031.012.8701.

Bird TJ, Bates AE, Lefcheck JS, Hill NA, Thomson RJ, Edgar GJ, et al. Statistical solutions for error and bias in global citizen science datasets. Biol Conserv. 2014;173:144-54. https://doi.org/10.1016/j.biocon.2013.07.037.

Cerini F, Stellati L, Luiselli L, Vignoli L. Long-term shifts in the communities of Odonata: effect of chance or climate change? North-West J Zool. 2020;16:1-6.

Corbet PS. Are Odonata useful as bioindicators? Libellula. 1993;12:91-102.

Cox J, Oh EY, Simmons B, Lintott C, Masters K, Greenhill A, et al. Defining and measuring success in online citizen science: a case study of zooniverse projects. Comput Sci Eng. 2015;17(4):28-41. https://doi.org/10.1109/MCSE.201 5.65 .

Dickinson JL, Shirk J, Bonter D, Bonney R, Crain RL, Martin J, et al. The current state of citizen science as a tool for ecological research and public engagement. Front Ecol Environ. 2012;10(6):291-7. https://doi.org/10.1890/11 0236.

Fourcade Y, Engler JO, Rodder D, Secondi J. Mapping species distributions with MAXENT using a geographically biased sample of presence data: a performance assessment of methods for correcting sampling bias. PLOS ONE. 2014;9(5):e97122. https://doi.org/10.1371/journal.pone.0097122.

Fuccillo KK, Crimmins TM, de Rivera CE, Elder TS. Assessing accuracy in citizen science-based plant phenology monitoring. Int J Biometeorol. 2014;59(7): 917-26. https://doi.org/10.1007/s00484-014-0892-7.

Grewe Y, Hof C, Dehling DM, Brandl R, Brändle M. Recent range shifts of European dragonflies provide support for an inverse relationship between habitat predictability and dispersal. Glob Ecol Biogeogr. 2013;22(4):403-9. https://doi.org/10.1111/geb.12004

Hassall C, Thompson DJ. The effects of environmental warming on Odonata: a review. Int J Odonatol. 2008;11(2):131-53. https://doi.org/10.1080/13887890.2 008.9748319.

Hickling R, Roy DB, Hill JK, Thomas CD. A northward shift of range margins in British Odonata. Glob Chang Biol. 2005;11(3):502-6. https://doi.org/10.1111/ j.1365-2486.2005.00904.x. 
Hijmans RJ, Cameron SE, Parra JL, Jones PG, Jarvis A. Very high resolution interpolated climate surfaces for global land areas. Int J Climatol. 2005;25(15): 1965-78. https://doi.org/10.1002/joc.1276.

Ishida S. Insects' Life in Japan. Vol. 2. Dragonflies. Tokyo: Hoikusha; 1969. Jung KS. Odonata of Korea. Seoul: Ilgongyuksa; 2007.

Kim CH, Kang JH, Kim M. Status and development of National Ecosystem Survey in Korea. J Environ Impact Assess. 2013;22(6):725-38. https://doi.org/10.1424 9/eia.2013.22.6.725

Kim MJ, Lee H, Ban YG, Lee SD, Kim DE. Prediction of changes in habitat distribution of the alfalfa weevil (Hypera postica) using RCP climate change scenarios. Korean J Appl Entomol. 2018;2018. https://doi.org/10.5656/KSAE.2 018.01.1.056

Kim Y, Shim KM, Jung MP, Choi IT, Kang KK. Study on the change of climate zone in South Korea by the climate change scenarios. Kor J Agric For Meteorol. 2017. https://doi.org/10.5532/KJAFM.2017.19.2.37

Kwon JM. The distribution of Lycaenid species in Korea according to climate factors. MS Thesis. Yeungnam University, Daegu-si, Korea; 2012.

Kwon TS, Lee CM, Kim SS. Northward range shifts in Korean butterflies. Clim Chan. 2014;126(1-2):163-74. https://doi.org/10.1007/s10584014-1212-2.

La Sorte FA, Lepczyk CA, Burnett JL, Hurlbert AH, Tingley MW, Zuckerberg B. Opportunities and challenges for big data ornithology. Condor. 2018;120(2): 414-26. https://doi.org/10.1650/CONDOR-17-206.1.

Lancaster LT, Dudaniec RY, Hansson B, Svensson El. Latitudinal shift in thermal niche breadth results from thermal release during a climatemediated range expansion. J Biogeogr. 2015;42(10):1953-63. https://doi. org/10.1111/jbi.12553.

Leach K, Montgomery WI, Reid N. Modelling the influence of biotic factors on species distribution patterns. Ecol Model. 2016;337:96-106. https://doi.org/1 0.1016/j.ecolmodel.2016.06.008.

Lee BY, Nam GH, Yun JH, Cho GY, Lee JS, Kim J-H, et al. Biological indicators to monitor responses against climate change in Korea. Korean J PI Taxon. 2010; 40(4):202-7. https://doi.org/10.11110/kjpt.2010.40.4.202.

Lee C-M, Kwon TS, Ji OY, Kim SS, Park GE, Lim JH. Prediction of abundance of forest flies (Diptera) according to climate scenarios RCP 4.5 and RCP 8.5 in South Korea. J Asia Pac Biodivers. 2015. https://doi.org/10.1016/j.ja pb.2015.10.009

Lee S, Jeon H, Kim M. Spatial distribution of butterflies in accordance with climate change in the Korean peninsula. Sustainability. 2020. https://doi.org/1 0.3390/su12051995.

Lewandowski EJ, Oberhauser KS. Butterfly citizen scientists in the United States increase their engagement in conservation. Biol Conserv. 2017. https://doi. org/10.1016/j.biocon.2015.07.029.

Loarie SR, Duffy PB, Hamilton H, Asner GP, Field CB, Ackerly DD. The velocity of climate change. Nature. 2009;462(7276):1052-5. https://doi.org/10.1038/na ture08649.

Lobo JM, Jiménez-Valverde A, Real R. AUC: a misleading measure of the performance of predictive distribution models. Glob Ecol Biogeogr. 2008; 17(2):145-51. https://doi.org/10.1111/j.1466-8238.2007.00358.x.

Moon J, Shim C, Jung OJ, Hong J-W, Han J, Song Y-I. Characteristics in regional climate change over South Korea for regional climate policy measures: based on long-term observations. J Clim Chan Res. 2020;11(6-2):755-70. https://doi. org/10.15531/KSCCR.2020.11.6.755.

Moore MP, Hersch K, Sricharoen C, Lee S, Reice C, Rice P, et al. Sex-specific ornament evolution is a consistent feature of climatic adaptation across space and time in dragonflies. PNAS. 2021;118(28):e2101458118. https://doi. org/10.1073/pnas.2101458118.

National Institute of Biological Resources. Operation of the Korea biodiversity observation network (K-BON) with civil participation II-1. Incheon: National Institute of Biological Resources; 2017.

National Institute of Biological Resources. The Guidebook of Climate Sensitive Biological Indicator Species. Seoul: Goryeo C\&P; 2019.

National Institute of Biological Resources. Operation of the Korea biodiversity observation network (K-BON) with civil participation (2020). Incheon: National Institute of Biological Resources; 2020.

National Institute of Meteorological Sciences. Global climate change forecast report. Jeju-do: National Institute of Meteorological Sciences; 2019.

Ožana S, Burda M, Hykel M, Malina M, Prášek M, Bárta D, et al. Dragonfly Hunter CZ: mobile application for biological species recognition in citizen science. PLoS ONE. 2019;14(1):e0210370. https://doi.org/10.1371/ journal.pone.0210370.
Pacifici M, Foden W, Visconti $P$, et al. Assessing species vulnerability to climate change. Nat Clim Chang. 2019. https://doi.org/10.1038/nclima te2448.

Park CY, Choi YE, Kwon YA, Kwon Jl, Lee HS. Studies on changes and future projections of subtropical climate zones and extreme temperature events over South Korea using high resolution climate change scenario based on PRIDE model. J Kor Assoc Reg Geogr. 2013;19:600-14.

Parmesan C, Yohe G. A globally coherent fingerprint of climate change impacts across natural systems. Nature. 2003;421(6918):37-42. https://doi.org/10.1038/ nature01286.

Pecl GT, Stuart-Smith J, Walsh P, Bray DJ, Martha K, Burgess M, et al. Redmap Australia: challenges and successes with a large-scale citizen science-based approach to ecological monitoring and community engagement on climate change. Front Mar Sci. 2019;6. https://doi.org/1 0.3389/fmars.2019.00349.

Phillips SJ, Anderson RP, Schapire RE. Maximum entropy modeling of species geographic distributions. Ecol Model. 2006;190(3-4):231-59. https://doi.org/1 0.1016/j.ecolmodel.2005.03.026.

Pocock MJO, Chandler M, Bonney R, Thornhill I, Albin A, August T, et al. Chapter six - a vision for global biodiversity monitoring with citizen science. Adv in Ecol Res. 2018. https://doi.org/10.1016/bs.aecr.2018.06.003.

Rapacciuolo G, Ball-Damerow JE, Zeilinger AR, Resh VH. Detecting long-term occupancy changes in Californian Odonates from natural history and citizen science records. Biodivers Conserv. 2017;26(12):2933-49. https://doi.org/10.1 007/s10531-017-1399-4

Ribera I, Vogler AP. Habitat type as a determinant of species range sizes: the example of lotic-lentic differences in aquatic Coleoptera. Biol Linn Soc. 2000;71(1):33-52. https://doi.org/10.1111/j.1095-8312.2000. tb01240.x

Roy-Dufresne E, Saltré F, Cooke BD, Mellin C, Mutze G, Cox T, et al. Modeling the distribution of a wide-ranging invasive species using the sampling efforts of expert and citizen scientists. Ecol Evol. 2019;9(19):11053-63. https://doi.org/1 0.1002/ece3.5609.

Sharma G, Clausnitzer V. Ischnura senegalensis. The IUCN red list of threatened species 2016: e.T59897A75436136.0; 2016. https://doi.org/10.2305/IUCN.UK.2 016-3.RLTS.T59897A75436136.en. Accessed 09 Sept 2020

Shin S, Kim JH, Dang JH, Seo IS, Lee BY. Elevational distribution ranges of vascular plant species in the Baekdudaegan mountain range, South Korea. J Ecol Environ. 2021;45(1). https://doi.org/10.1186/s41610-021-001 82-1.

Silvertown J. A new dawn for citizen science. Trends Ecol Evol. 2009;24(9):467-71. https://doi.org/10.1016/j.tree.2009.03.017.

Suhling F, Suhling I, Richter O. Temperature response of growth of larval dragonflies_an overview. Int J Odonatol. 2015;18(1):15-30. https://doi.org/1 $0.1080 / 13887890.2015 .1009392$

Suzuki-Ohno Y, Yokoyama J, Nakashizuka T, Kawata M. Utilization of photographs taken by citizens for estimating bumblebee distributions. Sci Rep. 2017;7(1): 11215. https://doi.org/10.1038/s41598-017-10581-x.

Termaat T, van Strien AJ, van Grunsven RHA, Knijf GD, Bjelke U, Burbach $\mathrm{K}$, et al. Distribution trends of European dragonflies under climate change. Divers Distrib. 2019;25(6):936-50. https://doi.org/10.1111/ ddi.12913.

Thapa A, Wu R, Hu Y, Nie Y, Singh PB, Khatiwada JR, et al. Predicting the potential distribution of the endangered red panda across its entire range using MaxEnt modeling. Ecol Evol. 2018;8(21):10542-54. https://doi.org/10.1 002/ece3.4526.

Urban MC, Bocedi G, Hendry AP, Mihoub JB, Pe'er G, Singer A, et al. Improving the forecast for biodiversity under climate change. Science. 2016;353(6304). https://doi.org/10.1126/science.aad8466.

van Vuuren DPV, Edmonds J, Kainuma M, Riahi K, Thomson A, Hibbard K, et al. The representative concentration pathways: an overview. Clim Chan. 2011; 109(1-2):5-31. https://doi.org/10.1007/s10584-011-0148-z.

VanDerWal J, Murphy HT, Kutt AS, Perkins GC, Bateman BL, Perry JJ, et al. Focus on poleward shifts in species' distribution underestimates the fingerprint of climate change. Nat Clim Chang. 2012;3(3):239-43. https://doi.org/10.1038/ nclimate1688.

Wang Y, Casajus N, Buddlle C, Berteaux D, Larrivée M. Predicting the distribution of poorly documented species, Northern black widow (Latrodectus variolus) and Black purse-web spider (Sphodros niger), using museum specimens and citizen science data. PLoS ONE. 2018;13(8):e0201094. https://doi.org/10.1371/ journal.pone.0201094 
Wiens JJ. Climate-related local extinctions are already widespread among plant and animal species. PLoS Biology. 2016;14(12):e2001104. https://doi.org/10.13 71/journal.pbio.2001104

Yum JH. Systematics of the Zygoptera (Odonata, Insecta) in Kore. Seoul: MS Thesis. Seoul Women's University; 2000.

Yum JW, Lee HY, Bae YJ. Taxonomic review of the Korean Zygoptera (Odonata). Bull Entomol Res. 2010;26:41-55.

\section{Publisher's Note}

Springer Nature remains neutral with regard to jurisdictional claims in published maps and institutional affiliations.

Ready to submit your research? Choose BMC and benefit from:

- fast, convenient online submission

- thorough peer review by experienced researchers in your field

- rapid publication on acceptance

- support for research data, including large and complex data types

- gold Open Access which fosters wider collaboration and increased citations

- maximum visibility for your research: over $100 \mathrm{M}$ website views per year

At BMC, research is always in progress.

Learn more biomedcentral.com/submissions 